\title{
Exploring the Emotional Intelligence Needs of University Lecturers in Managing Work-Related Challenges
}

\author{
Eucharia Chinwe Igbafe \\ Correspondence: Department of Psychology, University of South Africa, Pretoria, South Africa.
}

Received: April 21, 2020 Accepted: June 28, 2020 Online Published: July 28, 2020

doi:10.5539/res.v12n3p18 URL: https://doi.org/10.5539/res.v12n3p18

\begin{abstract}
The emotional intelligence needs of Nigerian university lecturers in managing work-related challenges were investigated in this study. A qualitative research approach of phenomenological interpretive design was used. Twelve university lecturers were selected purposively from three sampled Nigerian universities to participate in the research. The recorded interviews were transcribed and thereafter analysed with the assistance of ATLAS.ti 8 software. The four main themes that emerged were (a) struggling with regular work activities and emerging emotions, (b) finding a balance amidst many different demands and the lack of resources, (c) adaptability and adjustment problems, and (d) lack of emotional support from the university and possible reasons. The findings revealed that emotional intelligence needs regarding self-management and the management of relationships are present within the universities. The study also revealed that there is a need for institutional based policy to steer the addition of emotional intelligence exercise in academic systematic Professional improvement undertakings to ensure quality management of work challenges and the associated emotions. It is suggested that such training could be implemented through seminars and workshops in the various departments.
\end{abstract}

Keywords: emotional intelligence, higher-education work challenges, university lecturers

\section{Introduction}

University lecturers are professionals with approved rights to exercise autonomous and professional judgement (Hooley, 2007) in teaching, conducting research and engaging in community endeavours. The contributions of university lecturers are essential for the growth, integrity and ranking of the university and for bridging the gap between the students and the institution (Smith, 2008). University lecturers are among the most important contributors of quality education for sustainable development in Africa (Commission of the European Communities, 2006; Darling-Hammond \& Youngs, 2002). The quality of the knowledge, skills, attitudes and emotions of university lecturers plays an integral part in interpreting the programme of study, the selection of appropriate implementation strategies and learning support for students (Association for the Advancement of Sustainability in Higher Education, 2010; Organisation for Economic Cooperation and Development, 2014). University lecturers can passionately inspire students and direct them towards a deeper understanding of the course content for real-life applications (Coetzee \& Jansen, 2007). Therefore, university lecturers are pivotal in the provision of quality university education.

According to Makhanya (2007), university lecturers are the source of conducive learning environments and quality learning outcomes. Hence, university lecturers are important on many levels such as the planning, implementation and application of diverse teaching and research strategies (World Health Organization, 2011). Wang, Spalding, Klecka, and Odell (2011) further affirmed the importance of university lecturers when they stated that quality lecturers facilitate students' success with the use of teaching strategies that enhance the transfer of the intended knowledge and skills.

In contemporary times, promoting students' success in achieving national and international educational goals means that university lecturers particularly need to design teaching and learning objectives to equip students with the 21st-century "knowledge, values, skills, and behaviours needed to promote sustainable development" (United Nations Educational, Scientific and Cultural Organization [UNESCO], 2017, p. 19). In addition, university lecturers must provide support for every student, irrespective of their diversities (International Council for Open and Distance Education [ICDE], 2015). University lecturers are also expected to undertake the following responsibilities: (a) strengthen institutional management resources in human and financial contexts in order to address internal inequality in teaching and research (e.g. collaborate in the sharing of working resources) and engage in community development in an ethical, autonomous and responsible way; (b) provide equal opportunities for scientific and non-scientific forms of knowledge to promote interdisciplinary and transdisciplinary approaches; (c) produce an educational model that advances the development of critical and creative thinking and adaptability skills in diverse environments together with continuous course improvement; (d) identify 
teaching and learning strategies that promote dynamism and connection to real life; and (e) design strategies for teaching courses that accommodate the emerging profile of students and their unique potentials (Granados, 2019).

Glass (2014) asserts that despite common issues, there are a few specific localised challenges that universities encounter as a result of context and experiences. According to Sawahel (2017), these localised challenges include bridging the gap between scientific research and university education to cater to the requirements of the local labour market; increasing the culture of reading, research, innovation and the arts; and promoting meaningful utilisation of communications and information technology and e-learning in revitalising the education system, thus revolutionising instructional methods and broadening and advancing access to higher education.

In addition, although most African universities do not have the basic working resources to meet the teaching and research expectations, lecturers strive to ensure both quality and equity in research innovation, the co-publication of scientific articles and the sharing of resources to consolidate cooperation (Sawahel, 2017) regardless of the mismatch between higher-education outcomes and the job market (Sawahel, 2017).

Studies have shown that in most African countries and Nigeria in particular, over $90 \%$ of the populations of federal and state-owned institutions are working under poor conditions with limited resources (Babalola, Stouten, Euwema, \& Ovadje, 2018; Ogu, 2008) and dilapidated and poorly maintained facilities and structures (Lawanson \& Gede, 2011). Studies have also reported managerial styles that barely consider the emotional and psychological well-being of the lecturers (Egbochuku, 2012; Ofoegbu \& Nwadiani, 2006), resulting in increased workplace challenges and thereby exposing university lecturers to multiple vulnerabilities.

According to Zaidi (2014), vulnerability is conceptually situated at the intersection of limited work resources and the expectations of individuals. According to this perspective, university lecturers are vulnerable because they work with limited resources and do not expect working resources to be provided. Nathan (2009) maintains that vulnerability can occur in many contexts. According to Nathan (2009) and Zaidi (2014), university lecturers experience work challenges that expose them to diverse vulnerabilities. These vulnerabilities may include(a) research and publication vulnerability resulting from unavailability of modern laboratory instruments and chemicals for innovative research; (b) legal vulnerability resulting from weak legislature and judiciary regulations that compel the government to address the challenges of university education; (c) management vulnerability resulting from managerial styles that fail to source modern working equipment and provide better working conditions and work environments; and (d) emotional vulnerability resulting from the inability to prevent the pervasiveness of emotions in striving to adjust to work conditions and feelings of guilt resulting from lecturers' uncertainty regarding their expertise and moral integrity (Kelchtermans, 2006) in teaching without the basic resources.

From the preceding analysis, there is evidence that work-related challenges have been documented but the emotional intelligence needs of university lecturers in managing these challenges have been understudied. The little availability of literatures as regards to the emotional intelligence needs of university lecturers shows a lack of knowledge of how lecturers experience and manage these work-related challenges. Studies have reported that the ability to adapt and adjust reduces lecturers' vulnerability to work-related challenges (Griffin, Neal, \& Parker, 2007). Adaptability is the ability to engage in successful self-management through monitoring, controlling and directing feelings, actions and reactions (Collie, Holliman, \& Martin, 2017) to meet the challenging environment. Research has also shown that emotional intelligence contributes to adaptability in work environments (Coetzee \& Jansen, 2007). Despite the contribution of emotional intelligence to facilitate adaptability to the work environment, there are limited studies exploring the emotional intelligence needs of university lecturers in work-related challenges and how to ensure appropriate adaptability. To understand these needs, this study explored the experiences of work challenges and whether university lecturers had the necessary emotional intelligence to deal with such challenges.

\subsection{Emotional Intelligence}

First introduced by Salovey and Mayer (1990) the term emotional intelligence is defined as a group of social and emotional skills that affects how individuals recognize and articulate themselves, improve and sustain social relations, deal with challenges and utilise emotional information in an efficient and consequential way (Mayer, Salovey, \& Caruso, 2004). After extensive research, Mayer, Salovey, Caruso, and Sitarenios (2003) identified a few strategies that individuals can apply to promote emotional intelligence such as using emotional information to guide thinking and to manage actions while considering individual differences in emotional behaviour. McCarthy, Allen, and Jones (2013) maintain that emotional information derived from the work environment enables individuals to respect emotional diversity and value human rights, which contributes to the progression of non-violent divergence resolution and peaceable environments.

Bar-On (1997) found that using emotional intelligence helps individuals to thrive in managing work demands and pressures such as uncertainties and irritations. This is possible because building reciprocal interactions (Bronfenbrenner, 1994) and ethical relationships promotes teamwork and collaboration for better job performance (Goleman, 2004) and 
thus is an acceptable strategy in managing work-related challenges (Low\& Nelson,2006). Managing work-related challenges with emotional intelligence involves "self-motivation, persisting in the face of frustration, control impulse to act negatively, delay gratification, regulate personal mood and keep distressed from swamping the ability to think, to empathise and to hope" (Goleman, 1995, p. 34).

Studies have shown that rudiments of emotional intelligence such as self-management, self-awareness, social awareness and social skills contribute effectively in managing work-related situations (Boyatzis, Goleman, \& Rhee, 2000) because these elements have the capacity to support and improve work behaviour (Nelson et al., 2012), thereby increasing performance and productivity (Goleman, 2004). The abilities of emotional intelligence discussed here have implications for university lecturers in search of personal approaches in managing their work-related challenges (Coetzee \& Jansen, 2007).

Theorists of emotional intelligence have argued that the recognition, understanding and managing of situations with abilities of emotional intelligence contribute to the navigation of challenges to achieve victory (Bar-On, 2006; Goleman, 2004; Mayer et al., 2003). From the perspective of Goleman (1998) regarding the emotional intelligence theory of job performance, the learning, mastering and emotional intelligence application improves self-management, social awareness, self-awareness and relationship management, which helps the individual adapt to the workplace. Goleman (2004) maintains that the understanding and the knowledge derived from these abilities strengthen human determination, motivation and the power to navigate work challenges. According to Goleman (1995) emotional intelligence abilities needed for surmounting work challenges and ensuring high-quality performance include self-management, social awareness, self-awareness and relationship management. Earlier studies report the following:

- Self-awareness enhances the identification of emotional strengths, weaknesses and gaps in managing emotions through unbiased self-examination (Goleman, 2007; Nelson et al., 2012). Goleman (2007) explains that self-awareness helps humans and institutions to excel in performance and to attain quality in work productivity. According to Goleman (2004), self-awareness reveals a person's inner weaknesses and strength in handling emotional self-control to ensure adaptability

- Self-management involves self-awareness in controlling experienced emotions and impulses to react (Zeidner, Matthews, \& Roberts, 2004). Self-management is achieved through emotional self-control, flexibility and taking initiatives to address work-related challenges (Goleman, 2004).

- Social awareness is done by examining the social environment in other to identify and understand the level of empathy, politics and emotional cues that characterise the environment (Goleman, 2004).

- Relationship management involves teamwork, building bonds and reciprocal interactions that promote collaboration, solve problems and help others to develop in committed and dedicated ways (Boyatzis \& McKee, 2005; Cherniss \& Goleman, 2001) that result in outstanding performance and an increase in productivity.

A growing number of emotional intelligence scholars have challenged the use of Goleman's (1995) conceptualisations of emotional intelligence. Some of these scholars criticised the use of theoretical and scientific concepts that originate from a wide-ranging description of abilities (Hughes \& Evan, 2018) and the addition of different concepts such as emotional empathy, self-control, conflict management and innovativeness, leadership, social responsibility, orientation of service and teamwork (Bar-On, 1997). The critics of Goleman's (1995) concept of emotional intelligence also maintain that it includes variables without clear meanings, well-defined content and limitations (Hughes, 2018; Hughes \& Evans, 2018). However, disapprovals aside, little research if any has adopted Goleman's (2004) perception of emotional intelligence in capturing the emotional intelligence needs of university lecturers in managing work-related challenges.

\subsection{Emotional Intelligence Needs}

The concept of need is used to describe the gap between the present skills and the expected skills for an individual lecturer to function effectively in a work-challenged environment. The term need is considered important in initiating problem-solving programmes. According to Pushpanathan (2013), need analysis provides new knowledge that guides the design of programmes to address the identified needs. Gould, Kelly, White, and Chidgey (2003) explain that identification of needs involves an orderly exchange of ideas with a specific population to ensure effective preparation, implementation and assessment of the method of application and the results to ascertain future training needs.

Consequently, the exploration of needs would help to discover and understand the gaps, origins and the problems and pressures associated with the needs. Thus, the term emotional intelligence needs as used in this study defines the unavoidable requisite skills regarding the emotional intelligence that university lecturers need to attain in order to surmount and navigate the challenges in the work environment. Emotional intelligence needs are used to understand the needful skills and to give importance to the effect and the origin to effectively recognize the training requirements. 
Based on the above discourse, the current study aimed to bridge the gap in knowledge by using Goleman's (2004) emotional intelligence notion to identify and understand the emotional intelligence requirements of university lecturers in three different university settings, namely federal-owned, state-owned and privately owned. To achieve this aim, the study obtained information from the lecturers' responses to the research question: Do university lecturers have emotional intelligence needs for managing work-related challenges?

\section{Method}

\subsection{Research Approach and Strategy}

A qualitative research approach using an interpretive design was used to generate rich and in-depth data about the experience being investigated. Semi-structured individual interviews were utilised by the researcher to elicit the university lecturers' emotional intelligence requirements in the management work related difficulties. Each interview was conducted in the office of the lecturer lasting 45-60 minutes.

\subsubsection{Research Method and Setting}

The research and publication units and the heads of departments acted as gatekeepers and granted permission for the researcher to access the participants. The gatekeepers were provided with a group of criteria to direct purposive variety of the universities: a) founding year of Nigerian university; b) federal-, state- or privately owned university; and c) receipt of informed consent for the research to take place. Each university was assigned a code to ensure confidentiality and anonymity. The selected federal university, which is one of the oldest Nigerian universities, is located in a secure environment that can be easily accessed by road. The federal university was assigned the code 'FU'. The selected state university, one of the youngest universities in its category, within a short time has achieved. The state university was assigned the code 'SU'. The private university, which is a third-generation university, was assigned the code 'PU'. These three selected universities permitted their lecturers to participate voluntarily in the research.

\subsubsection{Researcher's Roles in the Research}

The researcher entered the participants' world as a 'collaborator in knowledge production' to elicit, analyse and interpret information with the intent of generating an improved perceptive of work-related challenges. The researcher adhered to the following process: a) a researcher-participant relationship was established by explaining the nature and the aim of the study and their part as a participant; b) the ethical concerns regarding anonymity and confidentiality were explained to the participants; c) participants were asked relevant questions to encourage in-depth answers relating to their personal situations; d) during the interviews, the researcher listened attentively to ensure proper understanding of the participants' experiences; and e) the subjective reality of the participants' accounts were interpreted.

\subsubsection{Research Site, Participants and Sampling Method}

After access to the participating universities was granted by the gatekeepers, the lecturers were asked to take part in the research. The criteria for selection were as follows: a) the university lecturer had to be a full-time academic staff member from one of the three selected Nigerian universities (federal, state and private); and b) the lecturer had to be engaged in teaching and research and have other responsibilities such as committee member or administrative duties.

In total, 24 lecturers at the federal university, 10 lecturers at the state university and 30 lecturers at the privately owned university expressed interest in the study. The participants were purposively sampled and selected, and the final number was 12 lecturers, four lecturers from each university type. Although, the number appeared small, the guiding principles of qualitative research allow 5-25 participants who have direct experience with the problem understudy to be purposively chosen (Creswell, 1998, 2007). Moreover, the reason for the relatively lower number of participants at the federal university than the privately owned university and the relatively low number at the state university was that at the time of this study, the university lecturers from these institutions were on an indefinite strike, which made most lecturers unavailable. Furthermore, most of the participants rejected the recording of the interviews because they maintained that their voices and experiences could be identified, despite the promises of anonymity and confidentiality. Hence, only lecturers who agreed to be interviewed and to have the interview audio taped were selected for this study.

From the lecturers who indicated interest after reading the objectives of the research, 12 were purposefully selected, four lecturers from each university. Purposive sampling was used to ensure that the selected lecturers had rich information on work-related challenges. The 12 selected lecturers signed a consent letter that contained detailed information regarding anonymity and voluntary participation. The socio-demographic data of the selected participants, that is, age, sex, marital status, university type, educational background and 'other descriptions' at the time of the study are presented in Table 1 using the assigned code names. The code names 'P' participant assigned number e.g. 1, 'FU': Federal university, 'SU': State University; 'PU': Private University. 
Table 1. Participant's socio-demographic background

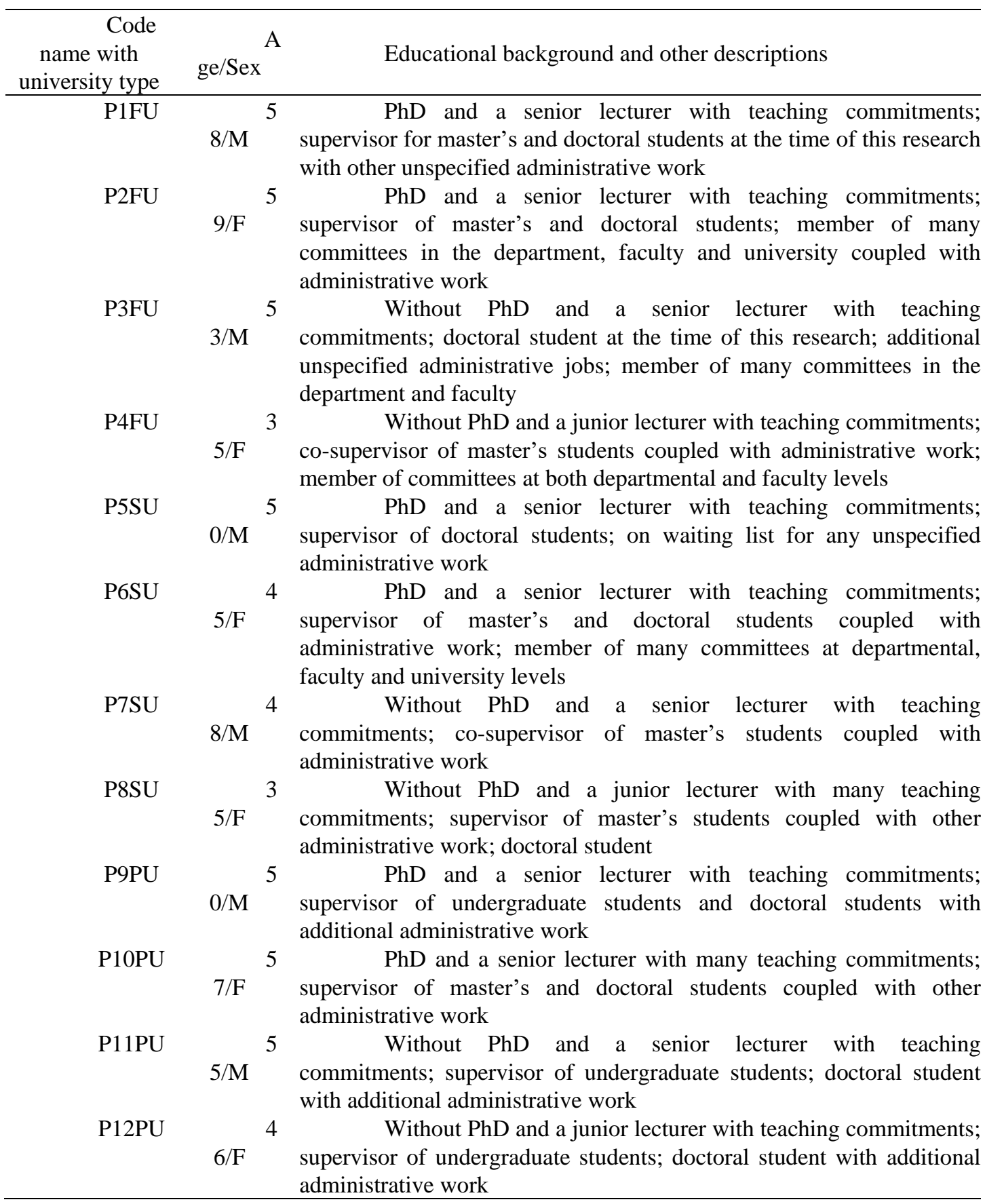

Marital status was not a criterion for selection. However, all the selected participants were married; none were widowed, divorced or separated.

\subsection{Data Collection Method}

English was used as the medium of communication. A semi-structured interview that consisted of questions posed in an unbiased manner was used to collect the data. Opportunities to ask follow-up questions to probe deeper were provided. To ensure that the interview questions were clear, easy to respond to and culturally relevant, a pilot study at each university was conducted, and the results were used to adjust the original questions. The pilot questions were used to test the suitability of the questions; hence the data obtained were used only for quality purposes. The interview questions and the possible secondary questions are presented in Table 2 . 
Table 2. Interview questions and secondary questions

\begin{tabular}{cc}
\hline Major questions & \multicolumn{2}{c}{ Possible secondary questions } \\
\hline Can you tell me if you have & \multicolumn{2}{c}{$\begin{array}{c}\text { Secondary questions focused on work } \\
\text { challenge as a conditions, work environment and work } \\
\text { facilities and structures related to teaching, } \\
\text { research and community engagement. }\end{array}$}
\end{tabular}

If so, did you manage the work-related challenges you experienced? Explain how?

Are you aware of the emotions that you experience due to work challenges? If yes, how do you manage the experience, if at all?
Secondary questions focused on the various ways that the participants adapted and adjusted to work-related challenges.

Secondary questions focused on the ways in which emotions and emotional intelligence were understood and applied.

\subsection{Data Recording}

As indicated in Table 1, each participant's interview information was allocated a code name to ensure anonymity.

\subsubsection{Strategies Employed to Ensure Data Quality and Integrity}

To ensure the trustworthiness and integrity of the collected data, pilot studies were conducted, and the Research Ethics Committee of the Faculty of Education at the University of Pretoria gave their approval. The same questions were asked at each interview, and probing questions were posed to enhance understanding of the participants' statements. Information emanating from the three universities was triangulated as suggested by Bryman (2012) in order to compare and match the emerging themes.

\subsection{Data Analysis}

The information collected from the participants through the individual semi-structured interviews was transcribed, organised and analysed using Creswell's (2007) five processes of qualitative data analysis. These are a) identifying key reoccurring texts; b) organising these texts into similar texts; c) comparing the texts across the participants' information; d) selecting the most reoccurring texts; and e) organising these texts into themes and sub-themes. To ensure trustworthiness in developing and organising the texts into themes and sub-themes, the transcribed data were revisited consistently as recommended by Bryman (2012). To ensure confirmability, the tape-recorded interviews and the transcribed information were revisited many times. This helped with the construction and reconstruction of the themes and the sub-themes that emerged.

\section{Findings}

This section presents emerged themes from the exploration of the emotional intelligence needs of the university lecturers concerning their work-related challenges. The four themes that emerged are presented in Table 3.

Table 3. Emergent themes

\section{Themes}

\section{Theme 1: Struggling with regular work activities and emerging emotions}

Theme 2: Finding a balance amidst many different demands and the lack of resources

Theme 3: Adaptability and adjustment problems

Theme 4: Lack of emotional support from university and possible reasons

\subsection{Theme 1: Struggling With Regular Work Activities and Emerging Emotions}

This theme explored the ways in which participants struggled with regular work activities and new demands. The participants identified three areas of struggle: (a) the need to organise work activities to accommodate additional roles (e.g. administrative functions) outside teaching and research duties; (b) the need to balance regular and unspecified roles such as being assigned to act as a member of a committee or to represent the department or faculty in a programme; and (c) the need to implement set plans and follow through to ensure their successful implementation.

Many of the participants commented on their struggles regarding regular work activities, the most significant among them being illustrated in the following extracted comments.

Sometimes, when I am called to attend emergency meetings or represent the department in an event outside the university, when I come back from such duties, I need to teach my courses I missed. Getting a free teaching space and time is difficult. I find that all the classrooms are occupied, and it will make me keep changing the date and time 
to teach the missed lecture. It makes me have crash lectures because I might have another lecture scheduled for the time I changed to. After the first and second hectic experience of searching for a class to teach, I developed procrastination, which increased my workload and frustration. (P1FU)

Participant P1FU provided an account of how unscheduled meetings interact with scheduled teaching times to create work challenges. In addition, the experience of challenges in trying to teach the missed lecturers was worsened due to limited workspace. The phrase "developed procrastination" can refer to succumbing to problems of limited workspace. Participant P1FU employed the word "procrastination" to describe the state of being overwhelmed with challenges and pinpointed increased workload as the cause of procrastination. Procrastination is the outcome of increased workload such as unscheduled meetings. Participant P1FU labelled frustration a felt emotion. The pressure of regular work activities had effects on the participants' emotions and work attitudes. The problem of limited teaching space was reported by some participants to be disruptive to planned teaching activities, thus encouraging procrastination:

Teaching space is one of our problem[s]. Lecturers like me who have additional responsibilities outside teaching and research are always facing disruptions of our organised activities. Struggling to get a teaching space has terrifying result[s] such as feeling helpless and mentally tasking. Another issue with limited teaching space is it encourages procrastination and increases the chances of not teaching that course unit. (P5SU)

Struggling with regular work activities and searching for teaching space were common sources of the apprehension and negative emotions experienced by the participants. Lecturers' anxieties emanated in part from their workload and their tendencies to procrastinate:

Apart from limited teaching space, I think research and publication is my greatest challenge. I am in science, [and] with unavailability of major laboratory instruments and chemicals for research, I end up publishing in local journals. I don't feel happy because my innovative ideas are not expanded with modern research equipment. The university management do not seek collaboration with the manufacturers of these [sic] science equipment to easy [sic] the challenges we experience in our faculty. Another general problem [the] lecturer has is weak legislature and judiciary to compel the government to support private universities financially for the betterment of university education. (P12PU)

The report of Participant P12PU shows differences in the experience of work challenges. She portrays the Faculty of Sciences as having different challenges because of the lack of modern laboratory equipment and chemicals for experiments. Her repeated emphasis on science and the need for university management to procure the required equipment shows the urgent need for teaching and research resources. The narrative of Participant P12PU shows helplessness due to failure of legislation to compel the government and university management to acquire teaching and research resources.

The poor work conditions that include limited teaching space and unavailability of vital teaching and research equipment produce multiple vulnerabilities for lecturers. The quotes extracted from participants P1FU, P5SU and P12PU show the frustrations and negative emotions that university lecturers endure in their attempts to ensure quality education. Hence, it could be interpreted that the lack of self-management skills generated procrastination and aggravated their workload, and ineffective relationship management hampered bonding and teaming with colleagues. Teaming with colleagues would enable the easy exchange of time schedules to reduce the search for available space, limiting procrastination and frustration. Emotional intelligence needs were highlighted as self-management and relationship management. Moreover, lecturers struggled to find a balance amidst the different demands of the old and the new emerging work challenges.

\subsection{Theme 2: Finding a Balance Amidst Different Demands and the Lack of Resources}

This theme represented participants' challenges in finding a balance amidst different work demands and the lack of resources across the participating universities. Work demands prominently mentioned were in the area of research, teaching and in other administrative roles that lecturers were called upon to perform. Indeed, most participants commented on their efforts to establish a sense of balance between teaching, research and publications. The most relevant is the following comment:

I have consistently struggled to balance teaching and research; it is too demanding. The senior lecturers who have published many papers both locally and internationally in journals are too busy to be mentors. It is a huge problem. Without publications, I am merely existing in the department, and a lack of publication is affecting my confidence because I have not published any paper. Again, new courses are being introduced; some of us are made to pick courses we are not trained to teach. I am not a multitasking person. (P3FU)

Participant P3FU describes the nature of the experienced work-related challenges as teaching, research and publication. He used the phrase "too demanding" to express the physical pressure of engaging in research and publication without 
the fundamental resources, the emotional pressure of failing to produce published papers and the social pressure as a result of little support from senior colleagues in areas of research and publication. Participant P3FU also used the phrase "multitasking person" to describe his inability to transit from a person who cannot multitask to a person who can adapt to a multitasking environment, thus privileging avoidance over making the effort to adjust. This participant further highlighted the lack of instruction for university staff before assigning them courses that they have not been trained to teach. Participant P3FU also reported that the workload of senior lecturers made them unavailable to provide teaching and research support for junior lecturers. Struggling to find a balance because of lack of initiatives and emotional flexibility in adjusting to work-related challenges is obvious. The account of Participant P3FU regarding the work challenges revealed the need for collaboration and teamwork to enable co-publications with senior and junior colleagues.

Another participant expressed the oppressive nature of experienced work challenges, especially when striving to balance regular work activities and the new demands imposed on lecturers:

I have talked to my colleagues, both senior and young, and I found we are trying to balance our regular work activities and [the] new demands placed on academics at this university. Our challenges are what to do about how we feel as lecturers without involving the trade union. A greater number of us feel the effect of having to work without the required instructional materials, having to balance teaching and research with administrative roles. When I want to teach practical work, the essential materials are not there. When I want to engage in research, the library is filled with outdated books. The university management knows there are some subjects one cannot teach without equipment. You see, I have also complained many times, and now the university introduced some courses that demand more equipment. (P7SU)

The narration of Participant P7SU began with generalising lecturers' experienced work challenges and subsequently positioned his challenges as personal experience. Participant P7SU used the phrase "new demands placed on academics at this university" to describe the current call for commitment to increase the design and teaching of student skills, values and behaviours for sustainable development in work or outside-work environments (UNESCO, 2017); to adopt more inclusive teaching and learning classes to accommodate students' academic, social, emotional and physical attributes (especially students with disabilities) (ICDE, 2015); and to place pressure on lecturers to increase the connection of their teaching and learning to real life (Granados, 2019). Participant P7SU elaborated on the struggles involved in teaching and conducting research with limited resources (Babalola et al., 2018; Ogu, 2008) and poorly equipped and maintained structures (Lawanson \& Gede, 2011). He expressed concern over the downplaying of the importance of working equipment by the university management, especially regarding their introduction of new courses, revealing helplessness and hopelessness in the lecturers. The concerns of Participant P7SU regarding placing new demands on lecturers without the required equipment were confirmed by another participant in the following comment:

The society is changing; the world is making new demands on academia. We don't have resources to meet these new demands, be it teaching, research or other administrative roles lecturers are called to perform. As a lecturer, I experience pressure. I feel sad and I feel guilty that I am not preparing my students with the right skills to face the world. In this helpless situation, we barely do nothing but persevere to keep suppressing our emotions, hoping that it will get better. (P9PU)

Participant P9PU used the word "feel" to describe the psychological experience after self-examination of work-related challenges and the pressure that ensued. Participant P9PU used "sad" to report the unavoidable feeling of disappointment with the university system for expecting new roles to be performed without provision of the corresponding new resources. This disappointment can also make one "feel guilty" that resources are not available for optimising students' skills (UNESCO, 2017). Feelings of guilt could also result from the inability to take the initiative and improvise teaching material and the failure to collaborate with colleagues within and outside the university to obtain or share teaching resources. The concluding statement of Participant P9PU emphasises exposure to different types of vulnerabilities (Nathan, 2009; Zaidi, 2014) and questions personal moral integrity (Kelchtermans, 2006) in teaching without the prerequisite resources. This account of work-related challenges suggests the need for self-management, emotional self-control, flexibility and initiatives, and social awareness (understanding the university social environment to recognise the level of empathy that characterises resource sharing and collaboration) (Goleman, 2004). In addition, relationship management to strengthen teamwork, to promote collaboration in resource sharing and to solve the problems of new job demands (Boyatzis \& McKee, 2005; Cherniss \& Goleman, 2001) is also suggested.

\subsection{Theme 3: Adaptability and Adjustment Problems}

Participants indicated the presence of adaptability and adjustment challenges for university lecturers. In the interviews, many of the participants mentioned that they had issues adapting and adjusting to the work challenges and the emotions that these challenges produced. Adapting to present demands and emerging new demands with limited working 
resources was identified as difficult, evoking feelings that led to anger, nervousness, fear, frustration and self-doubt among participants. The extracts from the participants' quotations demonstrate their perspectives on adaptability and adjustment problems:

Irrespective of my years of experience in the university, I find it difficult to adapt to teaching without the appropriate instructional materials. The university management knows that some instructional materials are unavoidable in some courses, yet they find it difficult to provide. I get angry most times and frustrated because over the years, I keep requesting for the instructional materials I urgently need to improve the quality of teaching and learning. So how do I adapt? Emotionally, it is not easy for me. Once I have [to] lecture, my emotions go up and down with fear of how my students perceive me. (P11PU)

The extract above evinces the struggles with adapting and adjusting to working without vital teaching materials. The fact that university management does not provide the required resources produces feelings of anger and frustration. The experienced emotions, which are sometimes difficult to control, lead to self-doubt regarding lecturers' professional integrity. This impedes their ability to adapt emotionally to work-related challenges. The extract below reveals another participant's view on the challenges of adjusting and her failed attempts, leading to feelings of self-doubt.

I have tried to surmount the challenges I experienced daily in this university. I have adopted [a] different attitude; I have applied mind disconnection in which I ignore the issues confronting me, but the approaches failed. Most time[s], I let out on students, especially when they complain they cannot hear me. My weakness is anger; having to request frequently for working materials without getting it [sic] is frustrating. The anger affects my relationships with colleagues and students. Again, being unable to teach my students, well, makes me doubt myself. (P4FU)

Participant P4FU used the phrase "mind disconnection" to explain the struggle in overcoming the experienced work challenges and emotions. Mind disconnection means reducing one's focus on the effects of the work challenges and diverting one's attention to other issues. The anger and frustration shown by participants emanated from their failure to engage in emotional self-control. Additionally, their self-doubt stemmed from their concerns relating to professional integrity and their inability to engage in appropriate self-management that builds self-confidence. Moreover, the participants were fearful that they would project their anger and frustration onto students and colleagues. The inability to adjust to limited instructional materials was found to increase anger and frustration, as is evident in the following extract:

I have tried to innovate ideas and develop methods of teaching practical in some of my courses. It never worked. If I have basic equipment and chemicals, I will be improvising other instructional materials. When the students asked me intelligent question, I realised that teaching students without crucial instruments and chemicals is dangerous to the society. Reflecting on my struggles to [sic] over the years, even before coming to this institution, I get frustrated and angry. (P10SU)

The extract from Participant P10SU shows that the inability to cope without the requisite instructional materials led to negative emotions. Frustration and anger were the consequences of the failure of diverse approaches to help her adaptability and adjustment to work challenges.

\subsection{Theme 4: Lack of Emotional Support From the University System}

At departmental and faculty levels participants disclosed no emotional support from the university, intensifying their negative emotions and disrupted their ability to manage work-related challenges. The following comments were extracted from participants across the selected universities:

Majority of us [lecturers] do not share the emotions we experience as we struggle with work challenges. This is because some colleagues will think one is complaining or lazy and not capable of doing the job. I get worried and wishes [sic] to share my feelings, but nobody cares. So, most of the time, I suppress the way I feel. Emotional expression is regarded as weakness and inability to tolerate challenges. (P4FU)

This participant often suppressed her emotions to avoid colleagues' attention. Suppression of expressions and discussion of felt emotions was due to fear of being perceived by colleagues as weak, lazy or unable to manage work challenges. In addition, the lack of emotional support increased lecturers' emotional weakness and their feelings of hopelessness in dealing with work challenges. Colleagues' lack of interest in the emotional issues of others was further emphasised in the following comment:

Colleagues are not interested in discussing emotional problems resulting from work challenges. Everyone expects me as a lecturer to deal with work issues; hence, it is embarrassing to say I am emotionally affected by work challenges. Suffering emotionally makes me feel like quitting. Again, knowing that I cannot obtain support from the university, both at departmental and faculty level, increases my sorrow. (P7SU) 
Participant P7SU described his reluctance to discuss felt emotions with colleagues because people assume that lecturers can deal with work challenges. It is evident that conversations on emotions promoted feelings of vulnerability. The emotional suppression and the failure to deal with their resulting emotions resulted in internal suffering. These negative emotions were intensified by a lack of support at departmental and faculty levels and led to the desire to resign. Some participants shared how they personally suffered on an emotional level:

I struggled emotionally trying to adjust to work condition[s] because I received no support. I feel frustration and angry when the challenges are pressuring. I needed support to enable me to navigate the work challenges. I realise that lecturers' emotions do not receive needed attention because many of us go through our job pretending, we are in control of our emotions. The truth is people like me struggle a lot. I cover up my emotions to appear in control before colleagues while I need emotional support. (P9PU)

In this theme, extracts from the participants across the selected universities illustrated that depending on colleagues for emotional support is not an option because the individual will be labelled lazy, weak and a complainer. Participants also mentioned that at university departmental and faculty levels, emotional support was not readily available because people assume that university lecturers can manage work challenges effectively without being overwhelmed by emotions. However, the participants across all the universities expressed difficulties in overcoming their emotions and described the resultant disruptions to adaptability. The participants' needs for emotional intelligence presented as a deep-rooted desire to manage the way they feel in their work environment. They wished that university management would provide emotional support and make appropriate teaching material available. Furthermore, the participants expressed the need for university lecturers to be able to disclose their emotions and to be encouraged to discuss them without fear of being labelled.

\section{Discussion}

This study explored the emotional intelligence needs of university lecturers in managing work-related challenges in three different categories of universities in Nigeria. The findings indicate that these emotional intelligence needs originated from lecturers' experiences of struggling with regular work activities and finding balance amidst the many different demands and the lack of resources. For most of the participants, their work conditions lacked the necessary resources and working space, which made them feel pressured and negatively affected their emotions.

To manage the experienced work-related challenges, lecturers need emotional intelligence to adapt and adjust within the university at both departmental and faculty levels. However, the findings of this study indicated that the participant universities do not have emotional support centres or programmes for strengthening the emotional intelligence of lecturers. To manage work challenges effectively, lecturers need to learn and master the necessary emotional skills and translate them into practice (Goleman, 2004). The extracts from the university lecturers in the present study revealed that the lecturers have emotional intelligence needs regarding self-awareness. The participating university lecturers were to a certain extent aware of their felt emotions, which included anger, anxiety, fear, frustration and self-doubt. However, management of the felt emotions was limited. Moreover, the lack of understanding of the emotional trends and the work-related challenges that trigger the emotions also made emotional management difficult.

The important findings of this study were a) three participants (P4FU; P7SU; P9PU) maintained that years of experience made them feel that they were impelled to suppress their emotions, and b) eleven participants reported experiences of anger, anxiety, fear, frustration and procrastination, which influenced their work performance and approaches to managing work-related challenges. Most of the university lecturers reported that they found it difficult to suppress their anger and anxiety. Anger and anxiety were experienced when university lecturers struggled to achieve quality performance amidst limited working resources, despite requests for vital instructional materials. Some of the university lecturers reported that they projected their anger onto colleagues and students. This expression of anger indicates the need for emotional intelligence because of its effect on functional relationships. This is in line with the findings of Sheehan and Jordan (2003) that uncontrolled emotions in work environments affect relationships and work performance. Many of the university lecturers reported fear and frustration. Fear and frustration were experienced when the lecturers were unable to manage work-related challenges, which led to procrastination. This finding of procrastination revealed that delay in addressing identified work-related challenges leads to procrastination. This agrees with the study of Svartdal, Granmo, and Færevaag (2018), which asserts that procrastination is a behaviour that limits implementations of planned activities.

The reported emotions suggest the need for self-management to increase emotional self-control and reduce impulsivity in displaying negative emotional behaviour (Goleman, 2004). University lecturers experienced self-management issues when struggling to adapt and adjust to work-related challenges. The struggle to adjust to working without vital instructional materials intensified the emotions experienced by the university lecturers. Limited teaching space, unscheduled additional responsibilities and the need to balance old and new work activities thwarted lecturers' ability to adapt. This is in line with the findings of Martin, Nejad, Colmar, Liem, and Collie (2015) that management of thoughts, 
actions and emotions is an effective strategy in navigating the demands of any given environment, thus ensuring adaptability. The university lecturers across the participating universities, irrespective of their educational background, age or sex, reported that they struggled with procrastination and workload because of unscheduled meetings and limited teaching space, which made adaptability difficult and increased emotional vulnerability. This finding indicates the need for emotional flexibility to enable lecturers to navigate work-related challenges in an acceptable way ( $\mathrm{Fu}, \mathrm{Chow}, \mathrm{Li}, \&$ Cong, 2018). This agrees with a study that reported that the ability to adapt and adjust to situations with a positive attitude and social skills is vital for effective adaptability (Holliman, Sheriston, Martin, Collie, \& Sayer, 2019).

This current study's findings also indicate that emotional intelligence is needed for recognising and understanding the problems of colleagues and to show empathy. The inability of university lecturers to identify, understand and sense the emotional state (Goleman, 2004) of colleagues made managing work-related challenges difficult for lecturers. The findings of this study revealed that the need for empathy arose when university lecturers were unable to share or discuss their emotions relating to work-related challenges for fear of being labelled lazy and a complainer. The reluctance to share or discuss felt emotions hampered the understanding of university management of the need for emotional support.

This current study's findings suggest that university lecturers need to strengthen working relationships with each other to facilitate collaborations in dealing with work-related challenges. According to Goleman (2004), building bonds improves teamwork, which in turn contributes to successful work performance and well-being. Furthermore, Goleman (2007) maintains that social interaction promotes better human connection and functionality, especially for individuals who spend a great deal of time within a system.

\section{Implications of the findings}

This study's theoretical implication for university lecturers and their institutions is to increase awareness and skills for emotional intelligence realistic. The implications for upcoming studies are as follows: a) addressing the sources of experienced work-related challenges; and b) initiating curative and preventive measures through emotional intelligence programmes.

\subsection{Addressing the Sources of Experienced Work-Related Challenges}

There is a need for university management to develop alternative means of acquiring working equipment by negotiating with private and public manufacturers to produce needful modern equipment at cost-effective rates. The vocational and technical department of the university should be supported in producing equipment. In addition, the universities should encourage lecturers to engage in research that focuses on producing vital instructional material for the university. Lecturers engaging in such research should be motivated to produce usable equipment.

Furthermore, each department should liaise with the local stakeholders to source basic working resources to reduce the work-related challenges. Alternatively, university management should collaborate with the federal, state or local government regarding the acquisition of basic resources. There is the need for the federal government to consider a budgetary allocation to universities that will ensure that prerequisite work resources are procured to lessen work challenges.

\subsection{Initiating Curative and Preventive Strategies Through Emotional Intelligence Programmes}

One of the main aims of emotional intelligence must be to provide curative strategies to university lecturers who experience distressing emotions because of work-related challenges. The purpose of emotional intelligence programmes should be to facilitate an improved understanding of the trends of emotional intelligence and the managing process. This means organising seminars and workshops that enable lecturers to recognise their individual emotional intelligence needs in managing experienced emotions and to learn to pay attention to the ways that emotions influence work behaviour and performance. Programmes should be constructed to produce a sense of healing and to reduce the severity of effects such as anxiety. By encouraging programmes from a curative point of view, lecturers will acquire the skills to apply emotional intelligence.

A preventive strategy refers to the means of safeguarding university lecturers against work-related challenges. A preventive strategy aimed at helping university lecturers to develop and strengthen their emotional intelligence for them to adapt and adjust to work-related challenges should be implemented. To fulfil this aim, there is a need for university management at both faculty and departmental levels to engage in exploring lecturers' emotional intelligence needs. Accordingly, emotional intelligence as a preventive measure should emphasis the acquisition and practical application of the skills to manage work emotions, behaviour and productivity. As a preventive strategy, emotional intelligence should be included in the departmental/faculty Continuing Professional Development programmes for academic staff. Seminars and workshops could be used to gain an enhanced perception of lecturers' emotional intelligence needs as well as the challenges that impede the valid application of emotional intelligence in handling with work-related difficulties. There is the need for policies at institutional levels to drive the addition of emotional intelligence exercise in 
the university curriculum and in the Continuing Professional Development programmes in order to develop, build up and develop the emotional intelligence of academic staff and thus ensuring self-sustenance expert compliance, amendment. This will help to reduce the work-related challenges that university lecturers experience.

\section{Conclusion}

This study explored the emotional intelligence needs of university lecturers in managing work-related challenges. Emotional intelligence needs reveal the gap between the present and the expected skills that the university lecturers in this study require to manage work-related challenges. Identification and understanding of emotional intelligence needs are necessary for adaptability and adjustment to existing and emerging work challenges. Continuous analysis of emotional intelligence needs would enable institutions to organise programmes that address identified needs. The programmes should be aimed at bridging the gap between available skills and needed skills.

Given the current emerging work-related difficulties, this study's findings highlight a gap exists between present skills and expected skills. Many of the participants reported experiences of work-related challenges, thus justifying the need for emotional intelligence.

\section{Ethical Clearance}

Ethical clearance to conduct the study was obtained from the Research Ethics Committee of the Faculty of Education, University of Pretoria, South Africa.

\section{Limitations of the study}

Three universities in Nigeria and 12 participants were sampled purposively from three different categories of universities in Nigeria, such as federal, state and private. The selection of three universities and 12 participants limited the generalisation of the findings of this study. Hence, there is need for more research with focus on university lecturers emotional intelligence using diverse research methodology.

\section{Acknowledgements and Conflict Of Interest}

The author acknowledges that no funding was received for the study and that there is no conflict of interest.

\section{References}

Association for the Advancement of Sustainability in Higher Education. (2010). Sustainability curriculum in higher education: A call to action. Denver, CO: Association for the Advancement of Sustainability in Higher Education. https://doi.org/10.5848/aashe.5747.2014.0003

Babalola, M. T., Stouten, J., Euwema, M. C., \& Ovadje, F. (2018). The relation between ethical leadership and workplace conflicts: The mediating role of employee resolution efficacy. Journal of Management, 44(5), 2037-2063. https://doi.org/10.1177/0149206316638163

Bar-On, R. (1997). The emotional intelligence inventory (EQ-i): Technical manual. Toronto, Canada: Multi-Health Systems.

Bar-On, R. (2006). The Bar-On model of emotional-social intelligence (ESI). Psicothema, 18, $13-25$.

Boyatzis, R. E., Goleman, D., \& Rhee, K. S. (2000). Clustering competence in emotional intelligence: Insights from the Emotional Competence Inventory (ECI). In R. Bar-On, \& J. D. A. Parker (Eds.), The handbook of emotional intelligence: Theory, development, assessment, and application at home, school, and in the workplace (pp. 343-362). San Francisco, CA: Jossey-Bass. https://doi.org/10.1016/S0160-2896(01)00084-8

Boyatzis, R., \& McKee, A. (2005). Resonant leadership. Boston: Harvard Business School Press.

Bronfenbrenner, U. (1994). Ecological models of human development. In U. Bronfenbrenner, T. Husen, \& T. N. Postlethwaite (Eds.), International Encyclopedia of Education, Vol. 3 (2nd ed., pp. 1643-1647). Oxford: Elsevier.

Bryman, A. (2012). Social research methods. (4th ed.). New York, NY: Oxford University Press.

Cherniss, C., \& Goleman, D. (Eds.). (2001). The emotionally intelligent workplace: How to select for, measure, and improve emotional intelligence in individuals, groups, and organizations. San Francisco: Jossey-Bass.

Coetzee, M., \& Jansen, C. (2007). Emotional intelligence in the classroom: The secret of happy teachers. Cape Town: Juta and Co.

Collie, R. J., Holliman, A. J., \& Martin, A. J. (2017). Adaptability, engagement and academic achievement at university. Educational Psychology, 37(5), 632-647. http://dx.doi.org/10.1080/01443410.2016.1231296

Commission of the European Communities. (2006). Communication from the commission to the council and to the European parliament: Efficiency and equity in European education and training systems. Brussels, 8.9.2006 COM 
(2006) 481 final. http://ec.europa.eu/ education/policies/2010/doc/comm481-en.pdf.

Creswell, J. W. (1998). Qualitative inquiry and research design: Choosing among five traditions. London: SAGE.

Creswell, J. W. (2007). Qualitative inquiry and research design: Choosing among five approaches. (2nd ed.). Thousand Oaks, CA: SAGE.

Darling-Hammond, L., \& Youngs, P. (2002). Defining "highly qualified teachers": What does "scientifically-based research" actually tell us? Educational Researcher, 31(9), 13-25. https://doi.org/10.3102/0013189X031009013

Egbochuku, E. O. (2012). Counselling and psychotherapy - the talking treatment: Discovery and creation within the counselling process. Inaugural Lecture Series 122. University of Benin, Nigeria, 15 March 2012.

Fu, F., Chow, A., Li, J., \& Cong, Z. (2018). Emotional flexibility: Development and application of a scale in adolescent earthquake survivors. Psychological Trauma: Theory, Research, Practice, and Policy, 10(2), 246-252. https://doi.org/10.1037/tra0000278

Glass, A. (2014). Foreword. In A. Glass (Ed.), The state of higher education 2014. The OECD Higher Education Programme (IMHE). Retrieved from www.oecd.org/edu/imhe

Goleman, D. (1995). Emotional intelligence. New York, NY: Bantam Books.

Goleman, D. (1998). Working with emotional intelligence. (1st ed.). New York: Bantam Books. https://doi.org/10.1002/lt1.40619981008

Goleman, D. (2004). Emotional intelligence and working with emotional intelligence (2nd ed.). London: Bloomsbury.

Goleman, D. (2007). Social intelligence. New York, NY: Bantam Books.

Gould, D., Kelly, D., White, I., Chidgey, J. (2004) Training needs analysis. A literature review and reappraisal. International Journal of Nursing Studies, 41(5), 471-486. https://doi.org/10.1016/j.ijnurstu.2003.12.003

Granados, J. (2019). The challenges of higher education in the 21st century. Barcelona: Global University Network for $\begin{array}{llllll}\text { Innovation } & \text { (GUNi). } & \text { Retrieved } & 24 & \text { July } & 2019\end{array}$ http://www.guninetwork.org/articles/challenges-higher-education-21st-century

Griffin, M. A., Neal, A., \& Parker, S. K. (2007). A new model of work role performance and positive behavior in uncertain and interdependent contexts. Academy of Management Journal, 50, 327-347. https://doi.org/10.5465/amj.2007.24634438

Holliman, A. J., Sheriston, L., Martin, A. J., Collie, R. J., \& Sayer, D. (2019). Adaptability: Does students' adjustment to university predict their mid-course academic achievement and satisfaction? Journal of Further and Higher Education, 43(10), 1444-1455. https://doi.org/10.1080/0309877X.2018.1491957

Hooley, N. (2007). Establishing professional identity: Narrative as curriculum for pre-service teacher education. Australian Journal of Teacher Education, 32(1), 49-60. https://doi.org/10.14221/ajte.2007v32n1.4

Hughes, D. J. (2018). Psychometric validity: Establishing the accuracy and appropriateness of psychometric measures. In P. Irwing, T. Booth, \& D. J. Hughes (Eds.), The Wiley handbook of psychometric testing: A multidisciplinary approach to survey, scale and test development (Vol. 2-2, pp. 751-779). Chichester: Wiley Blackwell. https://doi.org/10.1002/9781118489772

Hughes, D. J., \& Evans, T. R. (2018). Putting 'emotional intelligences' in their place: Introducing the integrated model of affect-related individual differences. Frontiers in Psychology, 9, 2155. https://doi.org/10.3389/fpsyg.2018.02155

International Council for Open and Distance Education. (2015). Higher education for the sustainable future we want: A call for action. 26th ICDE World Conference, ICDE Presidents' Summit and High-Level Policy Forum, 13-17 October 2015, University of South Africa, Pretoria, South Africa.

Kelchtermans, G. (2006). Teacher collaboration and collegiality as workplace conditions. A review. Zeitschrift für Pädagogik, 52(2), 220-237. URN: urn: nbn:de:0111-opus-44540

Lawanson, O. A., \& Gede, N. T. (2011). Provision and management of school facilities for the implementation of UBE programme. Journal of Education and Social Research, 1(4), 33-45.

Low, G. R., \& Nelson, D. B. (2006). Emotional intelligence and college success: A research-based assessment and intervention model. Kingsville, TX: Center for Education Development and Evaluation Research (CEDER).

Makhanya, M. (2007). Foreword. In M. Coetzee, \& C. A. Jansen (Eds.), Emotional intelligence in the classroom: The secrets of happy teachers. Cape Town: Juta and Co.

Martin, A.J., Nejad, H., Colmar, S., Liem, G. A. D., \& Collie, R. J. (2015). The role of adaptability in promoting control 
and reducing failure dynamics: A mediation model. Learning and Individual Differences, 38, 36-43. https://doi.org/10.1016/j.lindif.2015.02.004

Mayer, J. D., Salovey, P., \& Caruso, D. R. (2004). Emotional intelligence: Theory, findings, and implications. Psychological Inquiry, 15(3), 197-215. https://doi.org/10.1207/s15327965pli1503_02

Mayer, J. D., Salovey, P., Caruso, D. R., \& Sitarenios, G. (2003). Measuring emotional intelligence with the MSCEIT V2.0. Emotion, 3(1), 97-105. https://doi.org/10.1037/1528-3542.3.1.97

McCarthy, P. J., Allen, M. S., \& Jones, M. V. (2013). Emotions, cognitive interference, and concentration disruption in youth sport. Journal of Sports Sciences, 31(5), 505-515. https://doi.org/10.1080/02640414.2012.738303

Nathan, F. (2009). Natural disasters, vulnerability and human security. In H. G. Brauch, U. O. Spring, J. Grin, C. Mesjasz, P. Kameri-Mbote, N. C. Behera, ... H. Krummenacher (Eds.), Facing global environmental change (Hexagon Series on Human and Environmental Security and Peace, Vol. 4, pp. 1121-1129). Heidelberg: Springer. https://doi.org/10.1007/978-3-540-68488-6

Ofoegbu, F., \& Nwadiani, M. (2006). Level of perceived stress among lecturers in Nigerian universities. Journal of Industrial Psychology, 33(1), 66-75.

Ogu, E. (2008, September 30). Challenges facing Nigerian universities. Nigeriaworld. Retrieved 24 May 2011 from http//nigeriaworld.co/articles/2008/sep/300

Organisation for Economic Cooperation and Development. (2014). Perspectives on global development: Boosting productivity to meet the middle-income challenge. Technical Report. Paris: Organisation for Economic Cooperation and Development.

Pushpahathan, T. (2013). A need for needs analysis. International Journal of Applied Research \& Studies, 2(1), 1-6.

Salovey, P., \& Mayer, J. D. (1990). Emotional intelligence. Imagination, Cognition and Personality, 9(3), 185-211. https://doi.org/10.2190/DUGG-P24E-52WK-6CDG

Sawahel, W. (2017, January 13). Africa-Middle East: Higher education trends to watch in 2017. University World News:

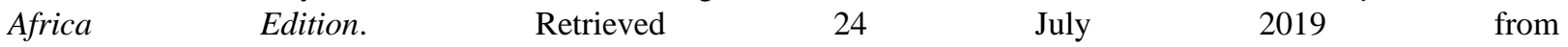
https://www.universityworldnews.com/post.php?story=20170113050746283

Sheehan, M., \& Jordan, P. (2003). Bullying, emotions and the learning organisation. In C. L. Cooper, S. Einarsen, H. Hoel, \& D. Zapf (Eds.), Bullying and emotional abuse in the workplace: International workplace: International perspectives in research and practice (pp. 359-369). London: Taylor \& Francis.

Smith, M. J. (2008). College choice process of the first-generation black female students: Encouraged to what end? Negro Educational Review, 59(3/4), 147-161.

Svartdal, F., Granmo, S., \& Færevaag, F. S. (2018). On the behavioral side of procrastination: Exploring behavioral delay in real-life settings. Frontiers in Psychology, 9,746. https://doi.org/10.3389/fpsyg.2018.00746

United Nations Educational, Scientific and Cultural Organization. (2017). Education for sustainable development goals: Learning objectives. Paris: United Nations Educational, Scientific and Cultural Organization. ISBN 978-92-3-100209-0

Wang, J., Lin, E., Spalding, E., Klecka, C. L., \& Odell, S. J. (2011). Quality teaching and teacher education: A kaleidoscope of notions. Journal of Teacher Education, 62(4), 331-338. https://doi.org/10.1177/0022487111409551

World Health Organization. (2011). World report on disability. Geneva, Switzerland: World Health Organization.

Zaidi, A. (2014). Life cycle transitions and vulnerabilities in old age: A review. (2014). Occasional Paper. UNDP Human Development Report Office.

Zeidner, M., Matthews, G., \& Roberts, R. D. (2004). Emotional intelligence in the workplace: A critical review. Applied Psychology, 53(3), 371-399. https://doi.org/10.1111/j.1464-0597.2004.00176.xs

\section{Copyrights}

Copyright for this article is retained by the author(s), with first publication rights granted to the journal.

This is an open-access article distributed under the terms and conditions of the Creative Commons Attribution license (http://creativecommons.org/licenses/by/4.0/). 